\title{
Surgical Treatment of A Premolar Case Retained In Inverted Position by Extra Buccal Access
}

\author{
Magnabosco Neto $\mathrm{AE}^{1^{*}}$,Gregio $\mathrm{SLP}^{2}$, Simm Filho JW $\mathrm{JW}^{3}$ \\ ${ }^{* 1}$ Department of Oral and Maxillofacial Surgery, Hospital São Hospital José - Joinville - Santa Catarina - Brazil \\ ${ }^{2}$ Department of Oral and Maxillofacial Surgery, Hospital Indaial - Indaial - Santa Catarina - Brazil \\ ${ }^{3}$ Department of Oral and Maxillofacial Surgery, Hospital São Hospital José - Jaraguá do Sul - Santa Catarina - Brazil
}

\begin{abstract}
Received: March 10, 2019; Accepted: March 20, 2019; Published: March 25, 2019
*Corresponding author: Dr Antonio Eugenio Magnabosco Neto, Blumenau Street 178, room 608,Centro, Joinville, Santa Catarina, Brazil. Tel: +55-4734334347; Email: aemagnabosco@terra.com.br
\end{abstract}

\begin{abstract}
Dental impaction is usually asymptomatic. In most cases it is recognized by chance by general dentists or orthodontists, when a patient arrives your office for a routine check-up. Mandibular third molars are the most commonly impacted teeth. Very few studies have been done to assess the prevalence of impacted premolars in inverted position. This study aims to approach the planning, diagnosis and surgical treatment of a case of premolar held in reverse position through extra oral access.
\end{abstract}

Key words: Tooth impaction; impacted premolars; pathology; migration; surgical treatment;

\section{Introduction}

An impacted tooth is one that fails to erupt into the dental arch within the expected time.1 Eruption of a tooth may be obstructed by adjacent tooth, dense bone or soft tissue and therefore may also cause impaction [2]. Teeth that do not erupt and do not develop in the proper functional position can be impacted. Nonfunctional, abnormal, or pathological impacted permanent teeth have a prevalence of 5.6-28.3\% and are considered a problem for all branches of dentistry [3-6]. In some occasions, these dental impactions, considered an eruptive failure mechanism, may result in malocclusions [7].

The order of frequency of dental impactions begins with the 3rd molars, followed by maxillary canines, mandibular premolars, mandibular canines, maxillary premolars, maxillary incisors and, finally, lower 2nd molars (lower incisors and 1st and 2nd molars jaws very rarely suffer from this anomaly) [67]. In this multifactorial etiology, the most common reason is the agglomeration of teeth lacking space for eruption. Lower third molars are the most commonly impacted teeth, but few studies have been conducted to evaluate the prevalence of impacted premolars. Migrated impacted premolars should be kept under observation and should only be removed if they are associated with the condition or if extraction is required for prosthetic or orthodontic treatment [8].

The human mandibular second premolar (MnP2) is highly variable developmentally, making it the most frequently absent tooth type, excluding the third molars [9].

The literature contains a limited number of case reports and comprehensive studies on retained and inverted premolars [10]. This study aimed to present a report of surgical case of pre-molar retained in reverse position, by extra buccal access.

\section{Clinical Surgical Case Report}

A 20-year-old female patient, P. S. B. leuco derma, was referred by the Orthodontist to the Bucomaxilofacial Surgery Clinic. At the intra-buccal examination, there was absence of the second lower premolars. When requesting a panoramic radiograph, the absence of the second right premolar (45) and the presence of a retained dental element (35) were evidenced in an inverted position, at the level of the base of the left jaw. At the extra-oral physical examination, there was no evidence of clinical changes. Computed tomography was requested to show the positioning of dental retention at the base of the mandible (Figure- 1 and Figure-2).

Due to the exteriorization of the tooth retained in the base of the mandible, it was proposed to perform the buccal exodontias surgery performed under general anesthesia.

Performed incision and detachment of the flap at the base of the left jaw and posterior ostectomy with drill bits attached to the hand piece of surgical motor, to expose the dental crown (Figure-3). The patient did not present postoperative sequels and the procedure was considered satisfactory. 

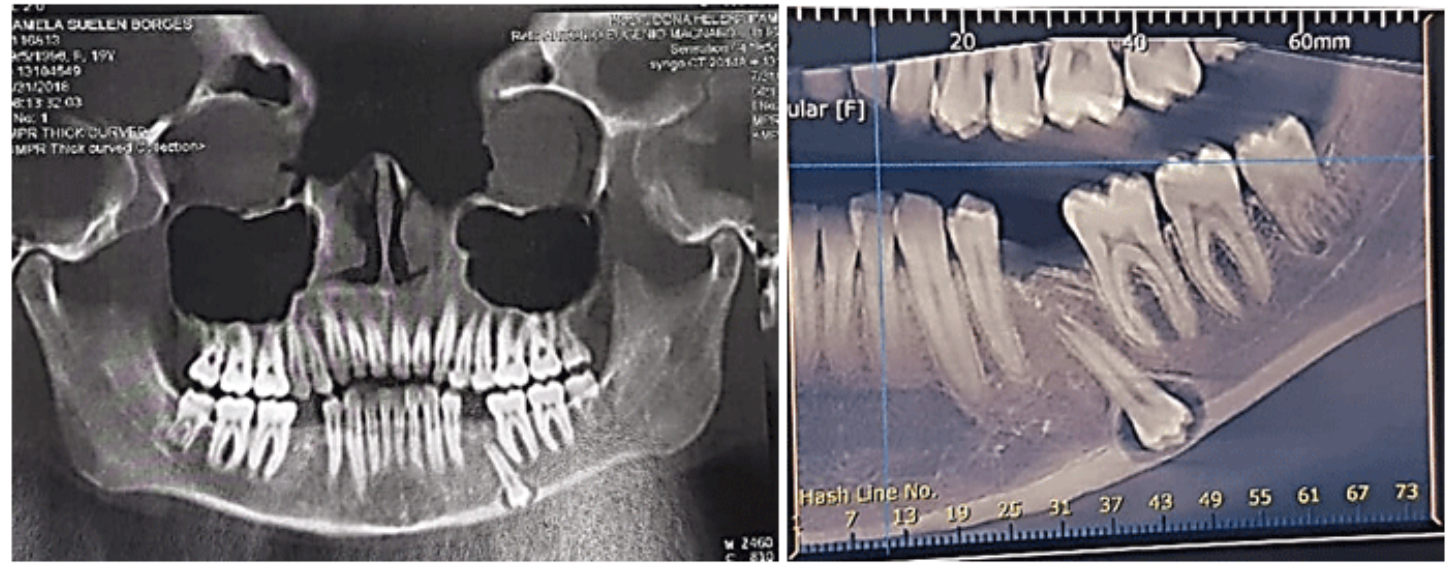

Figure 1: Tomographic appearance $t$ in Sagittal section.

*Source - Private collection of Prof. Dr. Antonio Eugenio Magnabosco Neto

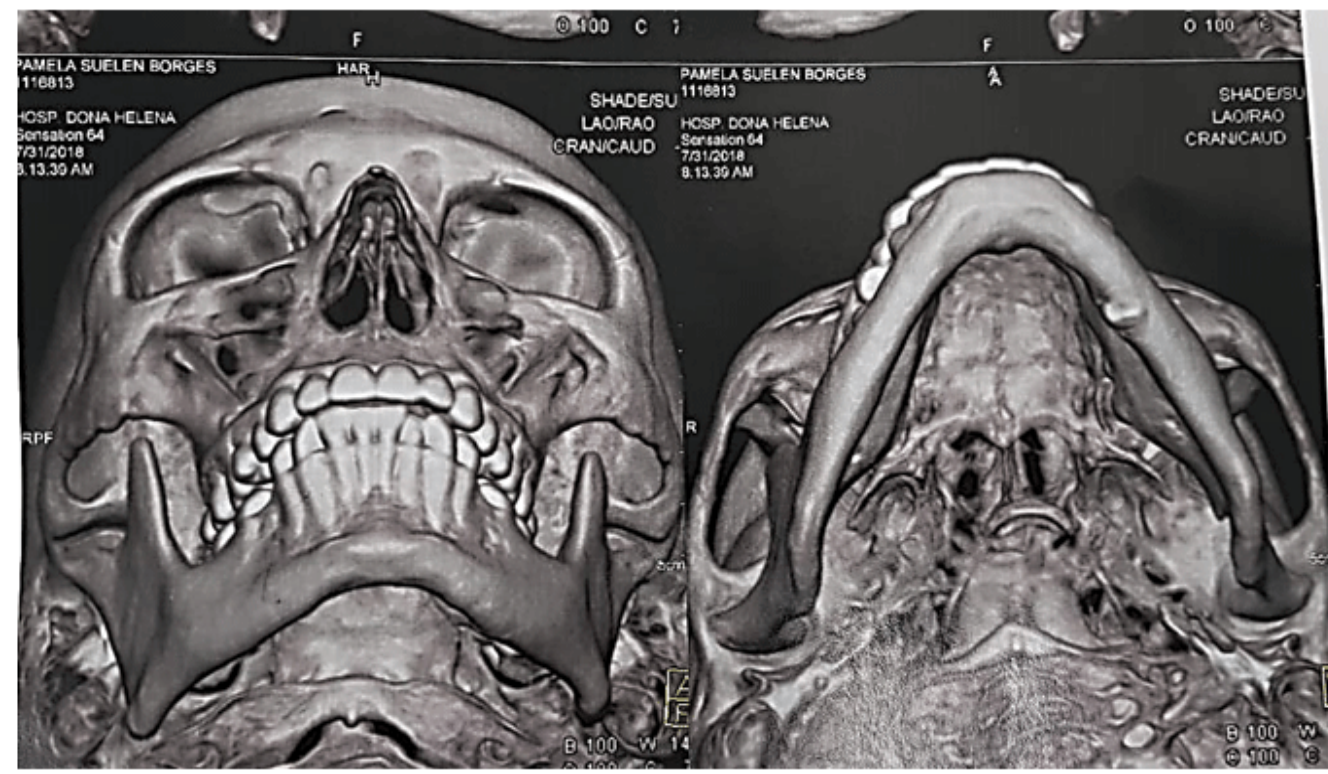

Figure 2: 3D tomographic appearance 


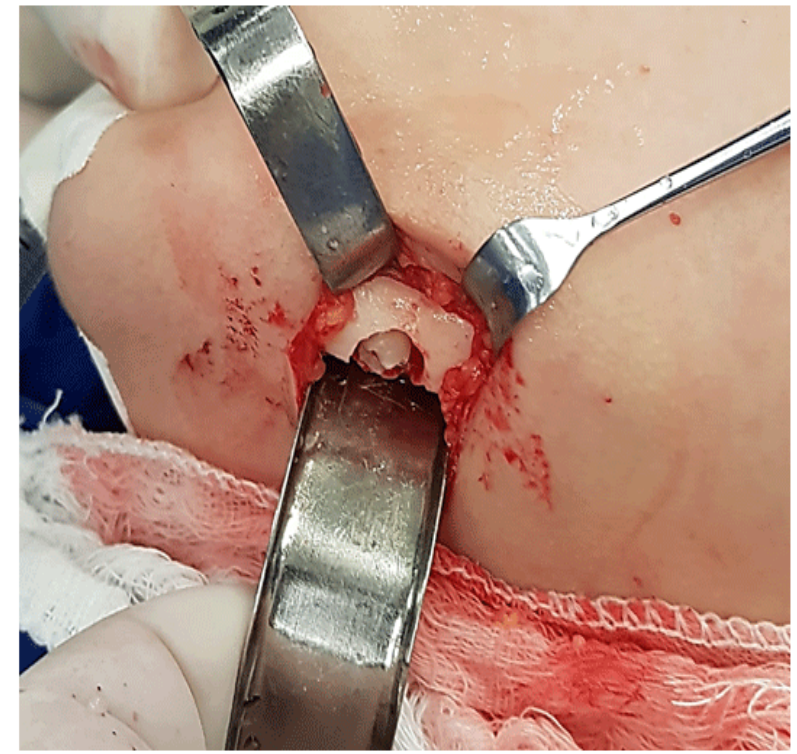

Figure 3: Detachment of the flap in the mandibular base and exposure of the retained tooth

\section{Discussion}

An impacted tooth is "a tooth that cannot or does not break into its normal operating positions and therefore is pathological and requires treatment" [1]. Any permanent tooth in the dental arch may be impacted, but the teeth most often involved in order the mandibular and maxillary third molars, the upper canines, the upper and lower second premolars, and the upper central incisors [2,6-7]. The lower third molars are the most frequently impacted teeth in humans, and surgical extraction has become one of the most common alveolar tooth surgeries [11]. The various types of impaction include vertical, horizontal, buccal, lingual and even inverted impaction [12]. The etiology of impaction is multifactorial [13]. Impaired teeth may be associated with periodontal disease, dental caries, odontogenic cyst and tumors, pain of unexplained origin, mandibular fracture and resorption of the root of the adjacent tooth [14].

The etiology of compaction of teeth other than third molars is poorly defined [2]. Intrusive trauma can cause impaction, especially when the periodontal ligaments are extensively damaged and common in the anterior segment. Fortunately, in young children, most of the teeth reappear. The eruption of a tooth can be obstructed by an adjacent tooth, dense bone or soft tissue, and therefore can also cause an impact [15]. Crowding in the vestibular segment may be due to tooth/arch size discrepancy or early loss of deciduous second molars in which no space maintainer is placed. This leads to insufficient space for the second premolars to erupt within the boundaries of the arch. Consequently, the second premolar usually erupts into a palatinal or lingually displaced position or may become impacted. The same is true in cases where there is a super-retained deciduous molar [14].
There are several theories to explain the occurrence of retained teeth. One is the discrepancy in the size of the jaw relative to the size of the tooth. Another theory that proves the occurrence of retained teeth is the change in eating habits that does not adequately stimulate mandibular growth and, therefore, the occurrence of impaction [15]. Most impacted premolar cases are reported accidentally in the routine screening of patients or when patients report to the dental clinic with some other problem [16]. Few impacted premolars are also advised to be removed by orthodontists prior to the commencement of fixed orthodontic treatment [10]. Aberrant tooth positions-such as infra occlusion, mesially ectopic maxillary first molar, palatally displaced canine, tooth transposition, and tooth rotation-are gaining attention as variables in a putative, genetically related pattern of dental anomalies [15].

The treatment of impacted teeth requires multidisciplinary cooperation between orthodontists, surgeons and sometimes periodontists. Orthodontic treatment and surgical exposure of the retained teeth are performed to bring the impacted tooth to the arch line [17].Theoretically, it is possible for any tooth to follow a disordered eruptive pathway and become impacted within the alveolar or heterotopic process in the anatomical sites, such as the nasal or sinus cavities, the mandibular ramus, or the lower border of the mandible. In addition, the teeth may not erupt due to direct or indirect effects of cysts and neoplasia or to abnormal hereditary patterns of phenotypic expression. Therefore, it is prudent to perform a complete clinical examination and to obtain adequate radiographs when the teeth do not appear according to the usual eruption schedule [18]. Teeth impacted for orthodontic protocol include exposure, repositioning, auto-transplantation and removal (Figure-4). Surgical approaches may involve an intraoral or extra-oral route, depending on the location of the tooth [18-19]. 
Occasionally a tooth extraction can be guaranteed depending on the etiology of the impacted and impacted specific tooth. The specific literature for impacted premolars is not extensive, even though the second lower premolars alone account for approximately $24 \%$ of all dental impingements [20].
However, if the tooth is in a position that is difficult to access, such as at the angle or the lower edge of the mandible, for example, extra oral removal may be more appropriate [19]. The etiology of dental impaction is multifactorial, requiring an interdisciplinary approach [17] making it difficult to choose the appropriate treatment for the cases of retained teeth with no possibility of repositioning in the dental arch.

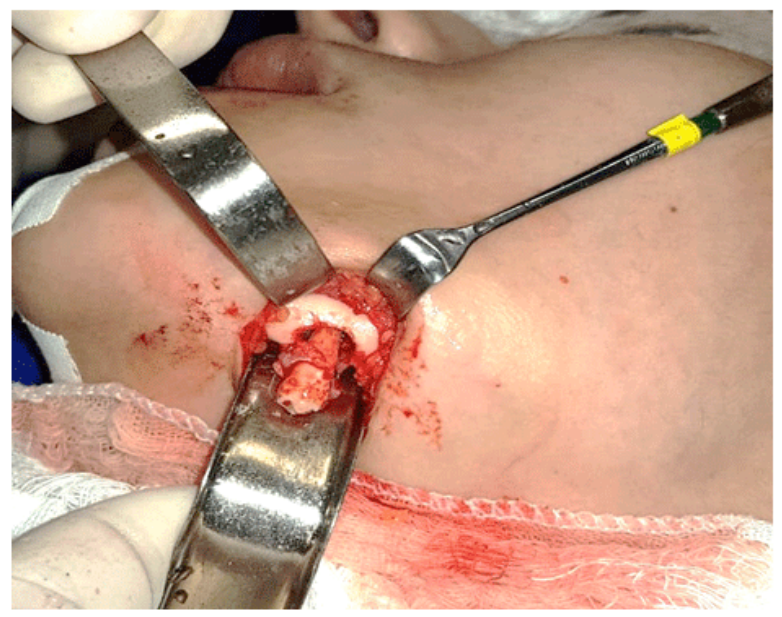

Figure 4: Removal of the premolar tooth

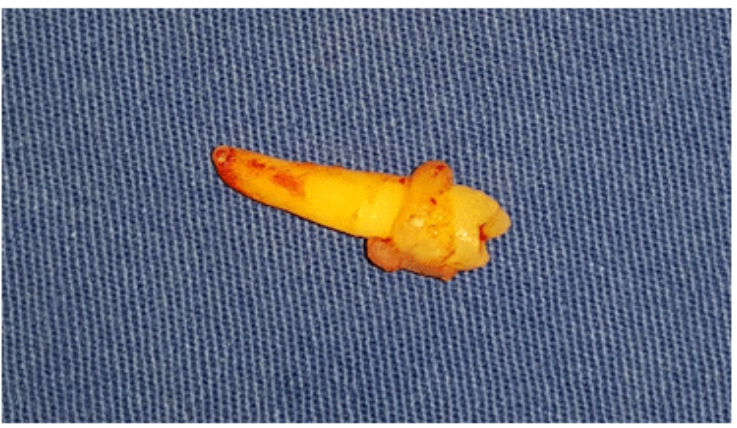

Figure 5: Aspect of the pre-molar tooth (35) removed

\section{Conclusion}

Early diagnosis of dental retention with ectopic eruptions allows the dental surgeon to make timely use of an interceptive treatment to avoid complications. In the surgical approach for the exposure of retained teeth, one should consider its anatomical position and if it presents satisfactory conditions must be included in orthodontic planning, when the positioning is unfavorable, it must be removed appropriately and with adequate planning.

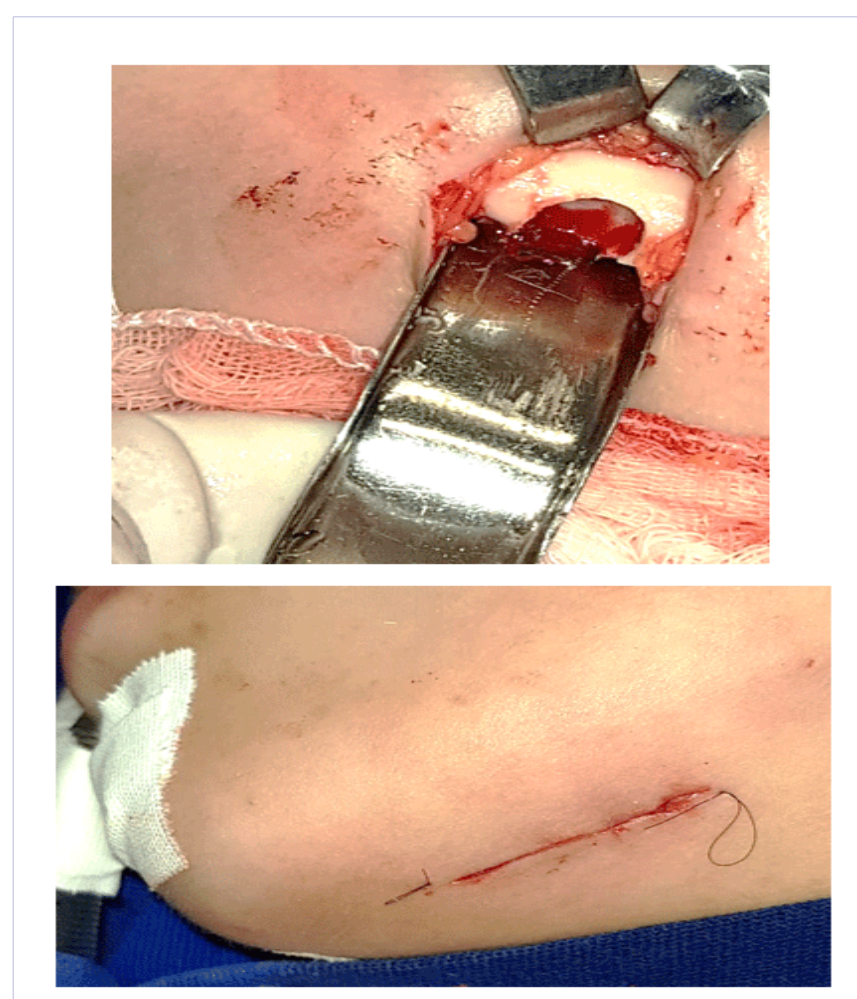

Figure 6: Surgical appearance after tissue layer extraction and suture. 


\section{References}

1. Peterson LJ, Ellis E, Hupp JR, Tucker MR. 1998. Contemporary Oral \& Maxillofacial Surgery; 4th ed. 1998; St. Louis: Mosby;156-8.

2. Al-Faleh W. Completely impacted teeth in dentate and edentulous Jaws. Pak Oral Dent J. 2009;29(2):255-260.

3. Obiechina AE, Arotiba JT, Fasola AO. Third molar impaction: evaluation of the symptoms and pattern of impaction of mandibular third molar teeth in Nigerians. Odontostomatol Trop. 2001;24:22-5.

4. Murray $\mathrm{P}$, Brown NL. The conservative approach to managing unerupted lower premolars -- two case reports. Int J Paediatr Dent. 2003;13(3):198-203.

5. Shapira Y, Borell G, Kuftinec MM, Stom D, Nahlieli O. Bringing impacted mandibular second premolars into occlusion. J Am Dent Assoc. 1996;127:1075-1078.

6. Lee PP. Impacted premolars. Dent Update. 2005;32:152-4,157.

7. Eliasson S, Heimdahl A, Nordenram A. Pathological changes related to long-term impaction of third molars. A radiographic study. Int J Oral Maxillofac Surg. 1989;18(4):210-212.

8. Şimşek-Kaya G, Melih-Ömezli M, Yapici G, Ertunç Dayı, Ümit Ertaş. Prevalence of impacted premolars in a Turkish population and considerations for surgical treatment. J. Med Oral Patol Oral Cir Bucal. 2011;16(6):e781-e786.

9. Shalish M, Peck S, Wasserstein A, Peck L. Malposition of unerupted mandibular second premolar associated with agenesisof its antimere. Am J Orthod Dentofacial Orthop. 2002;121(1):53-6.
10. Mustafa AB. Prevalence of Impacted PreMolar teeth in College of Dentistry, KingKhalid University, Abha, Kingdom of Saudi Arabia. J Int Oral Health. 2015;7(6):1-3.

11.Jaffar RO, Tin MM. Impacted mandibular third molars among patients attending hospital Universiti Sains Malaysia. Arch Orofac Sci. 2009;4(1):7-12.

12. Gisakis IG, Palamidakis FD, Farmakis RT, Kamberos G, Kamberos S Prevalence of impacted teeth in a Greek population. J Invest Clin Dent. 2011;2:102 109.

13. Tang AT. Impactions in adult dentition. Hong Kong Dent J. 2006;3(1):713.

14. Shalish M, Peck S, Wasserstein A, Peck L. Malposition of unerupted mandibular second premolar associated with agenesisof its antimere. Am J Orthod Dentofacial Orthop. 2002;121(1):53-6.

15. Liu RR, Tian J. Current situation of clinical research on impacted premolars. 2018;36(2):215-219.

16. KaczorUrbanowicz K, Zadurska M, Czochrowska E. Impacted Teeth: An Interdisciplinary Perspective. Adv Clin ExpMed. 2016;25(3):575585.

17. Alling CC 3rd, Catone GA. Management of impacted teeth. J Oral Maxillofac Surg. 1993;51(1 Suppl 1):3-6

18. Burch J, Ngan P, Hackman A. Diagnosis and treatment planning for unerupted premolars. Pediatr Dent.1994:16(2):89-95.

19. McNamara C, McNamara TG. Mandibular premolar impaction: 2 case reports. J Can Dent Assoc. 2005;71(11):859-863. 